\title{
Challenging the tyranny of impact factors
}

\section{A recent Commentary aroused a lively debate. In this issue we publish some responses.}

Sir - Peter A. Lawrence's Commentary "The politics of publication" (Nature 422, 259-261; 2003), about journal mania and the tyranny of impact factors, was like a breath of fresh air. How did this selfinflicted misery arise, and how on Earth are we going to get rid of it?

Clearly it arises largely from laziness and poor homework on the part of senior scientists and bureaucrats (the dividing line is sometimes thin). It is amazing how unscientific some of them can be once outside their own narrow field. Eugene Garfield, who invented the wretched impact factor, himself said that it is not appropriate for ranking individuals (see www.garfield. library.upenn.edu/papers/derunfallchirurg _v101(6)p413y1998english.html).

Astonishingly, these facts are not known (or are ignored) by some selection committees. Serious studies have been done, such as that of P. O. Seglen (Br. Med. J. 314, 498-502; 1997), which shows that the citation rate for individual papers is essentially uncorrelated to the impact factor of the journal in which it was published. This happens because of the very skewed distribution of citation rates, which means that high-impact journals get most of their citations from a few articles.

The distribution for Nature is shown in Fig. 1. Far from being gaussian, it is even more skewed than a geometric distribution; the mean number of citations is 114 , but $69 \%$ of papers have fewer than the mean, and $24 \%$ have fewer than 30 citations. One paper has 2,364 citations but 35 have 10 or fewer. (The Institute of Scientific Information, ISI, is guilty of the unsound statistical practice of characterizing a distribution by its mean only, with no indication of its shape or even its spread.) ISI data for citations in 2001 of the 858 papers published in Nature in 1999 show that the 80 most-cited papers $(16 \%$ of all papers) account for half of all the citations.

In my own work, for example, I have published a Nature (impact factor 27.9) article with only 57 citations, and an article in Philosophical Transactions of the Royal Society (impact factor 3.1) with more than 400 citations. Gratifyingly, this represents roughly my own assessment of the relative worth of the articles, but it emphasizes the ludicrousness of the recent current obsession with journal impact factors, especially at a time when, because of the Web, it matters less than ever before where an article is published.

Perhaps one way to cope with the problem is to turn it on its head. Candidates can judge institutions by the questions they ask, rather than the other way round. Any selection or promotion committee that asks you for impact factors is probably a second-rate organization. A good place will want to know about the quality of what you have written, not where you published it — and will be aware that the two things are uncorrelated. A useful method for job interviews that has been used in our department is to ask candidates to nominate their best three or four papers, then question them on the content of those papers. This selects against publication of over-condensed reports in high-impact journals (unless it is one of the relatively few genuinely important papers of this type). It also selects against 'salami slicing', and is a wonderful way to root out guest authors, another problem of the age. Experience has shown that candidates can have astonishingly little knowledge of the papers on which their names appear.

David Colquhoun

Department of Pharmacology, University College London, Gower Street, London WC1E 6BT, UK

\section{Editors are meant to be judges, not postmen}

Sir-Congratulations to Peter A. Lawrence $^{1}$ for his forceful denunciation in Commentary of the pernicious but pervasive view that publication in the 'right' journals is the same as publication of the best science. In particular, scientific editors who serve largely as postmen forwarding referees' comments to authors and expecting total compliance with referees' requests, however ill-judged, should respond to his plea that they revert to their proper function as judges both of the manuscript offered and of the referees' views. In my experience, there are still some proper editors, most often to be found on those learnedsociety-based journals that properly support their editors.

Lawrence elected "the original paper by Michael Berridge and Robin Irvine on phosphoinositol and cell signalling", published in 1984, to show that the difficulties of publishing 'in the right place' are far from new. But in doing so he dived straight into the 'overcompression of information' trap that he rightly castigates. Rather than citing the first paper to establish the role of inositol 1,4,5trisphosphate in $\mathrm{Ca}^{2+}$ signalling, he referred to a review that Berridge and Irvine wrote soon after. The original experimental paper ${ }^{2}$, also in Nature, had

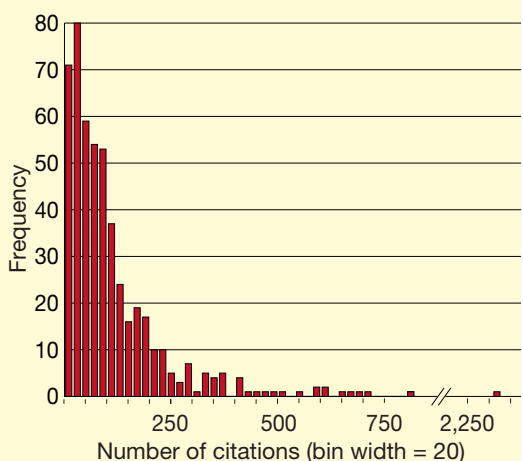

Figure 1 Distribution of the number of citations in five years for 500 biomedical papers published in Nature: 100 papers published in each of 1981, 1984, 1988, 1992 and 1996 were chosen at random, and for each paper the number of citations in the subsequent five years was counted. Data provided by Grant Lewison (Department of Information Science, City University, London EC1V 0HB, UK). four authors, and was far from the 'original' paper on this topic. The entire field started in 1953 (ref. 3), and notions of the possible involvement of inositol lipids and phosphates in signalling reactions go back to the late 1960s (ref. 4).

My experiences in dealing with Nature during the decade leading up to ref. 2 were frustrating but sometimes, in the longer term, beneficial. Once the idea that phosphoinositide breakdown is implicated in cell signalling had grabbed us, we envisaged inositol 1:2-cyclic phosphate as a signal in stimulated cells in a paper in Nature New Biology $y^{5}$ - we were wrong. Two more steps were essential before Streb et al. ${ }^{2}$ could home in on the $\mathrm{Ca}^{2+}$-mobilizing action of inositol 1,4,5trisphosphate. The first was to recognize a possibly causal relationship between receptor-driven phosphoinositide hydrolysis and $\mathrm{Ca}^{2+}$ mobilization ${ }^{6}$. Then we had to appreciate that receptor stimulation provokes $\operatorname{PtdIns}(4,5) \mathrm{P}_{2}$ hydrolysis ${ }^{7,8}$ rather than the hydrolysis of PtdIns that we had previously postulated ${ }^{6}$. It was the latter discovery that identified Ins $(1,4,5) \mathrm{P}_{3}$ as the likely product of the receptor-regulated phospholipase.

Both of these advances were first submitted to Nature and were rejected without reaching referees. On each occasion I was in the fortunate position of having an immediate opportunity to expound the new idea in detail in an 
invited review or symposium paper. As a result, the first impact of each paper may have been slower, but availability of a more detailed initial exposition than could have appeared in a 'top' journal probably helped the ideas to be understood more readily.

Bob Michell

School of Biosciences, University of Birmingham, Edgbaston, Birmingham B15 2TT, UK

1. Lawrence, P. A. Nature 422, 259-261 (2003).

2. Streb, H., Irvine, R. F., Berridge, M. J. \& Schulz, I. Nature 306, $67-69(1983)$

3. Hokin, M. R. \& Hokin, L. E. J. Biol. Chem. 203, 967-977 (1953)

4. Michell, R. H. in Phosphoinositides and Receptor Mechanisms (ed. Putney, J. W.) 1-24 (Alan R. Liss, New York, 1986).

5. Michell, R. H. \& Lapetina, E. G. Nature New Biol. 240, 258-260 (1972).

6. Michell, R. H. Biochim. Biophys. Acta 415, 81-147 (1975).

7. Creba, J. A. et al. Biochem. J. 212, 733-747 (1983).

8. Michell, R. H. Phil. Trans. R. Soc. Lond. B 296, 123-138 (1981).

\section{The system rewards a} dishonest approach

Sir - I strongly support the views of Peter A. Lawrence in his Commentary about the politics of publication (Nature 422, 259-261) and congratulate Nature for publishing this piece.

As Lawrence says, the assessment of science is, regrettably, moving towards an "audit society", in which the fact of having published in high-impact journals is seen as more important than the content of the papers themselves.

There are two further problems that arise from this assessment of individuals through the locations of their publications. First, only a minority of submissions get sent out for review in high-profile journals. As a regular reviewer for Nature, I find that submissions often contain some 'bold claim' about the extraordinary novelty of the results presented. These bold claims are designed to get the paper into the review process. In my experience, reviewers often find that the work in the manuscript is good science and quite interesting, but that the bold claim typically cannot be justified by the data that have been presented. The authors then dilute or remove the bold claim, with the result that a good, quite interesting manuscript is published, but is no better than many simultaneously being published in specialized journals. The difference is that the Nature submission began with hyperbole and overselling, the traces of which have vanished from the final version. There is a danger that authors are rewarded for a fundamentally dishonest approach.

Second, the review process has no power to screen for false authorship. Often, a large laboratory is likely to get one or more papers in high-impact journals, and it is very easy for the group leader to insert the name of a favoured postdoc who 'needs' a publication for some career goal into the list of authors, notwithstanding the minor contribution that the individual made to the work. The young scientist's CV is enhanced, and the rewards follow, not just for the young scientist, but also sometimes for the group leader.

\section{John Brookfield}

Institute of Genetics, University of Nottingham, Queens Medical Centre, Nottingham NG7 2UH, UK

Nature's authorship policy is that authors are strongly encouraged to include a statement in the Acknowledgements to specify the actual contribution of each co-author. See www.nature.com/nature/submit/ policies/index.html\#2 — Editor, Correspondence

\section{Impact factors aren't top journals' sole attraction}

Sir - Peter A. Lawrence (Nature 422, $259-261 ; 2003)$ points out in his Commentary that a substantial amount of politics has become commonplace in the scientific-publication enterprise.

In the numerous fields that are a bit less brutal than the highly competitive biomedical sciences, there may be another compelling motivation for authors to seek publication in the highest-ranked journals. The top journals are the most likely to consult top referees successfully, thus providing authors with the most meaningful feedback. The problem of fierce competition and conflicts of interest, although undeniably present, is probably less severe in fields such as the geosciences, and the benefit of receiving timely, topnotch reviews - rather than off-the-point comments from perhaps less qualified referees — should not be underestimated. Torbjörn E. Törnqvist

Department of Earth and Environmental Sciences, University of Illinois at Chicago, 845 West Taylor Street, Chicago, Illinois 60607-7059, USA

\section{Disruption to science in developing countries}

Sir - I fully agree with the concern expressed by Peter A. Lawrence in his Commentary (Nature 422, 259-261; 2003) about how different strategies and manoeuvres adopted by scientists desperate to publish in a few top journals can be disruptive to the quality of research. But in addition, the policy of considering "the journal to be more important than the scientific message" is having an even more devastating effect on science in developing countries.

I am speaking not only of my experience in Brazil, but also of other countries of similar social and economic standing, where money - and money for science - is much scarcer than in developed countries. Why is it worse here than there?

First, of course, there is much less money to be invested in science, and thus its misuse is proportionally more detrimental. Second, the 'accountability culture' has been imported and widely adopted, with neither assessment of its validity nor critical analysis of its consequences. It is troublesome that such an essential issue has been taken for granted by the scientific community, which by definition is supposed to accept facts and procedures only when solid data leave no space for doubt.

Finally, a numerical assessment of scientific merit minimizes the number of important variables, and consequently reduces the possibilities of defining the priorities and scientific strategies that best fit local demands.

I am fully aware of the international character of science and of the universality of the criteria for judging its quality. However, this global view does not mean that each country should forsake its individuality and its capacity to define its own criteria and methods for assessing merit.

Marcello A. Barcinski

Department of Parasitology, University of São Paulo, Av. Lineu Prestes 1374,

São Paulo 05508-900, Brasil

\section{Separate achievements of the Humboldt brothers}

Sir - In contrast to the assertion made in your Editorial "Berlin's university crisis" (Nature 423, 101; 2003), the famous principle of the "unity of teaching and research" that forms the conceptual basis of modern academic education was not developed by the natural scientist Alexander von Humboldt (1769-1859); neither was he the "founder of the modern German higher-education system".

These achievements were those of his brother, the politician and linguist Wilhelm von Humboldt (1767-1835), who in 1810 founded the university of Berlin that carries his name today.

W. S. Peters

Institut für Allgemeine Botanik,

Justus-von-Liebig-Universität, Senckenbergstrasse 17-21, D-35390 Gießen, Germany 